\title{
Editorial $^{+*}$
}

\section{Educação em ciências como campo político: Disputas atuais por projetos curriculares}

Este texto pretende ampliar o debate sobre política e educação em ciências, partindo da constatação de Moura (2019) de que posicionamentos políticos estão presentes na ciência e na educação em ciências. Se essa perspectiva ainda não está, de um modo geral, explicitamente incorporada pela maior parte dos trabalhos desenvolvidos na área, reflexões sobre o tema ainda são necessárias e precisam ser largamente empreendidas, investigando todas as suas potencialidades e possíveis entraves. Parto de vivências de insensibilidade política na prática da educação em ciências para então explorar caminhos para "a construção dessa educação em ciências mais politizada e politizante" (Moura, p. 3). Neste percurso, vejo como fundamental enxergar nosso campo como um campo político, no qual diferentes visões de ciência e de educação estão em confronto. Com essa perspectiva, pretendo avançar a discussão, expondo alternativas curriculares que fazem parte desse campo, tentando visualizar o papel da política nessas propostas e, alternativamente, a ausência de um papel político explícito na sua construção.

A experiência que vivenciei durante a sessão de abertura do VI Congreso Internacional sobre Investigación en la Didáctica de las Ciencias, em Barcelona, no dia 12 de setembro de 2001, me fez ter certeza que faltava algo muito importante naquele evento, considerando que o mesmo estava sendo realizado no dia seguinte ao ataque ao World Trade Center e ao Pentágono americano. Ouvi as falas de todos os participantes da mesa e a conferência de abertura, com a forte expectativa de que o acontecimento do dia anterior iria ser mencionado, mas isso não ocorreu! Entretanto, no intervalo, obviamente não se falava em outro assunto, como em qualquer outro lugar do planeta.

Em 2005, a sessão de abertura da edição seguinte desse mesmo evento foi bem mais estimulante no sentido de oferecer a percepção de uma educação em ciências menos isolada. O professor Jay Lemke abordou a educação científica a partir de um panorama teórico e conceitual renovado e aberto, que permitiu enxergá-la como um campo sociocultural e portanto carregado de particularidades psicológicas, filosóficas, sociais, políticas, culturais, cognitivas e econômicas, o que claramente tornava totalmente inapropriada a atitude apolítica, tão comum neste campo. O palestrante nos apresentou a abordagem sociocultural, que abriu perspectivas completamente novas no sentido de permitir pensar a educação em ciências em co-

\footnotetext{
${ }^{+}$Science Education as a Political Field: Current Disputes for Curriculum Projects

* Recebido: agosto de 2019.

Aceito: agosto de 2019.
} 
nexão com tudo o que está presente na realidade social.

Obviamente o divórcio entre a educação em ciências e o mundo político e social tem sido percebido e criticado em outros momentos, como mostra a vivência narrada por Bazzul (2012), durante a International History, Philosophy and Science Teaching Conference, realizada na Grécia, em 2011. O autor relata que muitos participantes, fora das salas onde estava ocorrendo a conferência, discutiam a situação socioeconômica da Grécia e as reformas neoliberais que estavam varrendo o país e outras partes do mundo e que notadamente, nenhuma conversa sobre este tema acontecia dentro dessas salas. Mais uma vez, foi significativo o fato de que dentro do espaço intelectual criado para a conferência não se falava de tais reformas; o desengajamento da educação científica com tais forças políticas era palpável. A partir dessa narrativa introdutória, Bazzul (2012) busca conceituar neoliberalismo e capitalismo global, de modo a poder mostrar a importância de pensar sobre ideologia, discurso e subjetividades para confrontar o neoliberalismo na educação em ciências.

Contudo, ainda que possa ser mais frequentemente percebido, o distanciamento entre educação em ciências e política ainda persiste entre nós. Considero que o prejuízo causado por esse divórcio não seja somente o de desestimular os jovens a enfrentarem esse tipo de debate, mas principalmente o de contribuir para a falsa ideia de que nas ciências da natureza não há política.

Talvez a influência mais significativa sobre a educação em ciências no sentido de propiciar análises políticas tenha sido o movimento social Ciência-Tecnologia-Sociedade (CTS). Articulado ao currículo, voltou-se, inicialmente, para as inter-relações entre explicação científica, planejamento tecnológico, solução de problemas e tomada de decisões sobre temas de importância social (Roberts, citado por Santos e Mortimer, 2002). Recentemente, a reflexão sobre a abordagem curricular CTS tem sido complexificada e outros aspectos têm ganhado ênfase em sua conceituação. Por exemplo, Santos e Auler (2019) apontam a necessidade de se problematizar a suposta neutralidade da ciência-tecnologia, colocando como alvo desse questionamento, a dimensão axiológica, que em geral é ignorada, principalmente na definição da agenda que dá forma ao direcionamento do desenvolvimento científico-tecnológico. Os autores também alertam para a concepção equivocada de que a tecnologia é neutra e que seus perigos são decorrentes de seu mau uso, lembrando que determinados interesses e valores moldam características de produtos científico-tecnológicos que se manifestam independentemente de um suposto bom ou mau uso. Sugerem que essas questões sejam problematizadas no contexto educacional por meio de encaminhamentos da abordagem CTS aproximados ao pensamento crítico de Paulo Freire. Ainda que os autores visualizem direcionamentos consistentes para a construção dessa aproximação, como possibilidades de estruturação interdisciplinar do currículo em torno de temas/problemas reais e democratização de processos decisórios, reconhecem que o movimento CTS enquanto projeto curricular é polissêmico, dando margem também, à produção de encaminhamentos metodológicos incompatíveis com a perspectiva Freireana. 
Do mesmo modo, a expressão alfabetização científica, cada vez mais usada na educação em ciências, pode carregar diferentes sentidos. Muitas vezes é entendida como a aprendizagem do conhecimento ou da linguagem científica para que os indivíduos consigam lidar com uma sociedade cada vez mais tecnológica. Entretanto, essa expressão pode assumir um viés crítico, passando a ser expressa como letramento científico (Santos, 2007), para enfatizar seu vínculo ao domínio da prática social e sua aproximação com a função social da educação científica.

A introdução de temas ambientais, políticos, econômicos, éticos, sociais e culturais relativos à ciência e à tecnologia na educação científica pode ser uma estratégia vinculada à abordagem curricular CTS ou pode ser desenvolvida de forma independente. Em qualquer dos casos, Mortimer \& Santos (2009) têm enfatizado a necessidade da abordagem desses temas, denominados de sociocientíficos, no sentido de promover a ressignificação da função social do ensino de ciências, com o objetivo de desenvolver atitudes e valores em uma perspectiva humanística Freireana. Embora seja uma proposta curricular tão próxima à abordagem CTS, a utilização dos temas sociocientíficos ainda é pouco presente na literatura brasileira.

Para além do propósito de preparar os cidadãos para a sociedade tecnológica, Santos (2009) acredita que é necessário perceber a educação científica como tendo uma função sociopolítica. Para o autor, recuperar a pedagogia crítica proposta por Paulo Freire para aplicá-la ao ensino da ciência é construir uma visão mais radical da educação científica humanista, na perspectiva de uma educação que possa alterar a desigualdade social do mundo globalizado, particularmente no âmbito da alfabetização científica e tecnológica.

Por outro lado, vemos também crescer, no campo da educação em ciências, abordagens curriculares tradicionais, que se preocupam com a eficiência dos meios para atingir objetivos pré-determinados, ou a formação profissional. Trazemos, como exemplo, a proposta curricular de renovação do ensino de ciências (Cachapuz et al, 2005) por meio do ensino por investigação, concebida com base em um conjunto de $\operatorname{artigos}^{1}$ de pesquisadores nacionais e internacionais atualizados e reelaborados. É interessante analisar o percurso conceitual da discussão preliminar em torno de diferentes significados atribuídos à alfabetização científica, até ser concebida aquela que irá balizar a referida proposta. Inicialmente, os autores defendem a alfabetização científica para todos os cidadãos, reconhecendo, com base em Bybee (citado por Cachapuz et al, 2005) que o uso dessa expressão sofre de ambiguidade, permitindo a cada pessoa atribuir-lhe significados distintos, que levariam a diferentes objetivos. Os autores trazem diferentes entendimentos sobre a alfabetização científico-tecnológica e apresentam a conceituação de Aikenhead (citado por Cachapuz et al, 2005), que consideram expressar convergência dos seguintes aspectos da alfabetização científica: "a necessidade de ir além da habitual transmissão de conhecimentos científicos, de incluir uma aproximação à natureza da

\footnotetext{
${ }^{1}$ Como os capítulos do livro são textos baseados em artigos publicados e não reproduções dos artigos na íntegra, optamos por apresentar a referência bibliográfica como se o livro não fosse um livro organizado (no qual os capítulos teriam autorias diferentes).
} 
ciência e à prática científica e, sobretudo, de enfatizar as relações ciência-tecnologiasociedade-ambiente, de modo a favorecer a participação dos cidadãos na tomada fundamentada de decisões" (p. 23).

Outros direcionamentos da alfabetização científica são explorados, como por exemplo, a tese pragmática (Fensham, citado por Cachapuz et al, 2005), que defende que os futuros cidadãos precisariam adquirir uma base de conhecimentos científicos dada a grande influência das ideias e produtos da ciência e da tecnologia na sociedade contemporânea. Contra essa tese, o próprio autor reconhece que os utilizadores dos produtos tecnológicos não têm "nenhuma necessidade de conhecer os princípios científicos em que se baseiam para os poder utilizar" (p. 24). Fensham (citado por Cachapuz et al, 2005) também critica a chamada tese democrática, de que a alfabetização científica permitiria aos cidadãos participarem das decisões que a sociedade deveria tomar em torno de questões sociocientíficas, por considerar uma ilusão acreditar que o nível de conhecimento científico implicado em problemas como o aquecimento global, por exemplo, possa ser adquirido nos anos de escolarização obrigatória.

Os autores passam a mostrar, ao contrário do que argumenta Fensham (citado por Cachapuz et al, 2005), que com um mínimo de conhecimentos específicos acessível a todos, abordagens globais e considerações éticas é possível compreender as opções em jogo e participar na adoção de decisões fundamentadas. Relatos de problemas sociocientíficos, como por exemplo, o do uso de fertilizantes químicos, o armazenamento de resíduos radioativos, a utilização dos CFCs e o caso dos alimentos transgênicos são apontados como alvos de críticas exercidas por cidadãos e grupos de ativistas informados. Até este ponto do texto a participação dos cidadãos na tomada de decisões é considerada positiva, garantindo a precaução face aos riscos do desenvolvimento tecnocientífico para as pessoas ou para o meio ambiente e um mínimo de formação científica que permitisse a compreensão dos problemas e das opções expressos em linguagem acessível.

Entretanto, embora tal proposta constitua um argumento decisivo a favor da alfabetização científica do conjunto dos cidadãos, não é, para os autores, suficiente para combater críticas usuais ao ensino de ciências, como as acusações de dogmatismo, abstração formalista, carência de significado, que segundo os autores se devem "ao modo como o ensino apresenta habitualmente essas matérias" (p. 30). Propõem então, um método alternativo ao ensino de ciências criticado e passam a descrever o modelo de ensino por investigação, que poderia recuperar aspectos históricos da ciência, relações CTS-Ambiente e assim devolver à aprendizagem de ciências "a vitalidade e relevância do próprio desenvolvimento científico" (p. 30), tendo como objeto problemas abertos e a construção de soluções. Os autores acreditam que este modelo de aprendizagem será capaz de contemplar tanto a alfabetização para todos quanto a formação de futuros cientistas.

Na segunda parte do livro, os autores criticam visões deformadas da ciência e da tecnologia que incluem a descontextualização, a concepção elitista, a concepção empíricoindutivista, a visão rígida e infalível e a visão aproblemática e ahistórica, para então propor 
uma reorientação epistemológica da educação em ciências que, "numa perspectiva tipo Popperiana" (p. 95), pretende, por meio do método hipotético-dedutivo, "aproximar a ciência dos cientistas da ciência praticada na sala de aula" (p. 95) e levar à aquisição de conhecimentos teóricos, à aprendizagem sobre a natureza das ciências e à prática da ciência. $\mathrm{O}$ ensino por investigação corresponderia assim, a uma investigação orientada, em áreas conhecidas pelo professor, e "onde os resultados parciais e embrionários obtidos pelos alunos podem ser reforçados, completados ou até mesmo questionados" (p. 113). Na proposta apresentada, a aprendizagem é correspondentemente concebida como "um processo de pesquisa orientado que leva os alunos a participarem na (re)construção do conhecimento científico, favorecendo uma aprendizagem mais significativa e eficiente" (p. 120). Nesta configuração, fica claro que os problemas a serem investigados têm como objeto conceitos e leis científicas, finalidade bem distante da que se pretendia com os problemas sociocientíficos tratados na parte inicial do livro. Desse modo, a proposta não consegue atingir a unificação entre os objetivos da alfabetização científica e os da formação de futuros cientistas.

Também nos dois últimos capítulos do livro, que visam à aplicação do ensino de ciências por investigação, percebe-se que na prática também não há tal unificação. Visando ao ensino dos conceitos de trabalho e energia, são apresentadas perguntas e solicitações de exemplos cujo conteúdo é semelhante ao dos livros-texto habituais. No último capítulo, são apresentadas perguntas e atividades tendo como objeto problemas sociocientíficos relativos à degradação da vida no planeta, à perda da diversidade cultural, ao desenvolvimento sustentável e aos direitos humanos. Ambos os capítulos se voltam sobre si mesmos, sem conseguirem construir relações entre conceitos científicos e problemas sociocientíficos. Reificam assim, o afastamento entre, de um lado, um ensino experimental de conceitos científicos que serve à habitual transmissão de conhecimentos e de outro, a exposição de problemas sociocientíficos que preocupam a humanidade. Considerando a proposta de ensino de ciências por investigação como um todo, não se percebem tentativas de conectar alfabetização científica para todos e formação científica para futuros cientistas, como pretendido inicialmente.

No conjunto de propostas curriculares abordadas neste editorial, foi possível enxergar a contraposição entre uma perspectiva técnica (defesa do conhecimento em si) e uma perspectiva crítica (defesa do conhecimento para fazer algo). Na medida em que tanto uma perspectiva como a outra tomam o conhecimento apenas como produto sócio-histórico que faz parte do currículo e não como prática de significação, o que daria margem a propostas bem mais fluidas e abertas, a própria definição de educação escolar acaba, em ambas, sendo subsumida à ideia de ensino (Macedo, 2012). Tal crítica, ainda que pertinente no âmbito do breve panorama traçado aqui, talvez não deva ser assimilada de imediato, por uma comunidade cuja produção parece desconectada das questões sociopolíticas inerentes à ciência e à educação em ciências e que ainda precisa avançar na direção de propostas críticas. A apropriação de um olhar político e social ainda representa algo novo e que portanto, precisa progredir.

A partir de uma postura pós-crítica do currículo (Lopes, 2013), é possível observar o 
campo da educação científica como campo de luta, no qual, de acordo com o nosso recorte, o letramento científico, a proposta curricular CTS e a abordagem das questões sociocientíficas fazem parte de uma visão contra-hegemônica, que se volta para as finalidades do currículo, enquanto tantas outras propostas, ainda que se pretendam inovadoras, apenas se dedicam ao "o quê" e ao "como" ensinar o conhecimento em si. O ensino de ciências por investigação, tendo como objeto problemas que são usualmente investigados em laboratórios, não avança no sentido de se conectar com a realidade sociocientífica ou de explorar relações CTSA, mencionadas em sua elaboração. Neste caso, fica igualmente reduzido a uma inovação pedagógica, que faz do estudante de ciências um mini-cientista alienado do mundo social, que "investiga" os fenômenos da natureza, em um processo de redescoberta das leis de uma ciência neutra.

Acredito que, a partir de um ensino de ciências neutro, focado no conhecimento em si, não seja possível avançar com as lutas sociais e políticas, o que equivale a sermos coniventes com o atual cenário social da pobreza, da educação abandonada e de decisões sociocientíficas prejudiciais ao ambiente e a todos nós. É bom termos em mente que um projeto curricular com suas características singulares ganha materialidade em contextos reais, resultando em formas diferentes de enfrentar os problemas da realidade social na arena da luta política. Esse processo, enquanto prática discursiva, desloca a ação política para a luta pelo significado dos projetos de educação científica realizados por cada um de nós, o que, segundo Lopes (2013), representa nossa possibilidade de esperança.

\section{Referências}

BAZZUL, J. Neoliberal ideology, global capitalismo, and Science education: engaging the quetion of subjectivity. Cultural Studies of Science Education, 7, p. 1001-1020, 2012.

CACHAPUZ, A.; GIL-PÉREZ, D.; CARVALHO, A. M.; PRAIA, J.; VILCHES, A. (2005). A necessária renovação do ensino das ciências. SP: Cortez Editora.

LOPES, A. C. Teorias pós-críticas, política e currículo. Educação, Sociedade \& Culturas, v. 39, p. 7-23, 2013.

MACEDO, E. Currículo e conhecimento: abordagens entre educação e ensino. Cadernos de pesquisa, v. 42, n. 147, p. 716-737, 2012.

MOURA, C. O ensino de ciências e a justiça social - questões para o debate. Caderno Brasileiro de Ensino de Física, v. 36, n. 1, p. 1-7, 2019.

MORTIMER, E. F.; SANTOS, W. L. P. Abordagem de aspectos sociocientíficos em aulas de ciências: possibilidades e limitações. Investigações em Ensino de Ciências, v. 14, n. 2, p. 191-218, 2009. 
SANTOS, W. L. P.; MORTIMER, E. F. Uma análise de pressupostos teóricos da abordagem CTS (Ciência-Tecnologia-Sociedade) no contexto da educação brasileira. Ensaio - Pesq. em Ed. em Ciências, v. 2, n. 2, p. 1-23, 2002.

SANTOS, W. L. P. Educação científica na perspectiva de letramento como prática social: funções, princípios e desafios. Revista Brasileira de Educação, v. 12, n. 36, p. 474-492, 2007.

SANTOS, W. L. P. Scientific literacy: a Freirean perspective as a radical view of humanistic science education, Science Education, v. 93, p. 361-382, 2009.

SANTOS, R. A.; AULER, D. Práticas educativas CTS: busca de uma participação social para além da avaliação de impactos da Ciência-Tecnologia na sociedade. Ciência \& Educação, v. 25, n. 2, p. 485-503, 2019.

\section{Flavia Rezende ${ }^{2}$}

Programa de Pós-graduação em Ensino de Física

Instituto de Física - UFRGS, RS

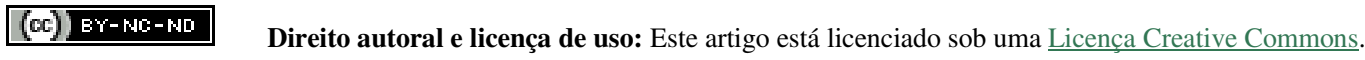

\footnotetext{
${ }^{2}$ E-mail: flaviarezende@uol.com.br
} 